\title{
Improving Electrical Energy Consumption by Application of Integrated Starter Generator for Single Cylinder Engine Applications
}

\author{
Samarth Jain ${ }^{1}$ \\ Advance Engineering, Research and Development \\ Greaves Cotton Ltd, Akurdi Chowk, Old Mumbai- Pune \\ Highway. Chinchwad, Pune- 411019 India
}

\author{
Kedar Kanase ${ }^{3}$ \\ Advance Engineering, Research and Development \\ Greaves Cotton Ltd, Akurdi Chowk, Old Mumbai- Pune \\ Highway. Chinchwad, Pune- 411019 India
}

\author{
Phaneesh $\mathrm{K}^{2}$ \\ Advance Engineering, Research and Development \\ Greaves Cotton Ltd, Akurdi Chowk, Old Mumbai- Pune Highway. \\ Chinchwad, Pune- 411019 India
}

\begin{abstract}
Electrical loads on an engine are increasing as engines are operated intelligently with mechanical, electrical and electronic combinations. These increased electrical loads are due to improvements of safety, comfort electric control and also for stringent emission requirements. In this paper the efficiency of the flywheel rotor assembly by using better integrated starter generators (ISG) are being investigated. [3] This paper is aimed to explore the improvements in electrical energy consumption by the application ISG. With the application of Flywheel Magneto type ISG, there is improved efficiency over the conventional starting and charging system. Emphasis is on reducing the electrical energy consumption and improving conversion efficiency. The electrical energy generated by converting mechanical energy needs better conversion efficiency. This in turn helps in lower fuel consumption as this electrical energy is basically developed by fuel energy. So any improvements in conservation of this energy finally help in conserving the fuel which in turn helps in reducing the $\mathrm{CO} 2$ emission.
\end{abstract}

Keywords- Flywheel Integrated Starter Generator, ISG, Electrical Energy Improvements, Three wheeler applications, Single Cylinder Engine, Charging Efficiency.

\section{INTRODUCTION}

There has been an almost exponential increase in the electrical power requirement of automobiles in the past years. More electric driven systems will replace or assist mechanical components. This trend is going to increase in the future generation of automobiles.

The demand of electrical energy nearly doubled when engine shifted from mechanical system to electronic fuel managements systems. The projection is next generation three wheelers vehicles can have maximum electric load of 2 $\mathrm{kW}$ with the present $12 \mathrm{~V}$ system, the electric load demand in commercial automobiles can increase to about $5 \mathrm{~kW}$ or more in the next 10 years. The dramatic increase in auxiliary power demands requires substantial changes in the existing electrical generation system in automobiles. Latest trend in this regard is the concept of using a single machine in a bi- directional power flow electromechanical system, such as an integrated starter and generator (ISG) system. This system appears attractive for automotive and other mobile applications where space and weight reduction is of critical importance.[6] Also it gives an impetus to move towards the hybrid vehicles by a progressive phase wise shift to mild hybrids to plug hybrids or to even electric vehicles

The ever-increasing consumer demands and stringent regulations on emissions and fuel consumption drove the automotive OEMs to re-engineer the drivetrain of the vehicle. This has ranged from engine downsizing, and innovative solutions that improve the efficiency of ICEs to various levels of drivetrain electrification/hybridization. The overall efficiency improvement is a key discussion point across the globe. At the same three wheelers are needed for our way of living for last mile connectivity in Indian sub-continent. The areas of improvement were friction reduction, reduction in pumping losses, use of on demand water or oil pumps, and improvement in electrical conversion efficiency. The electrical energy required to run the engine is generated by engine on the consume power from the fuel and alternator is used to convert mechanical to electrical energy. Also considerable electrical energy is required for engine cranking. With a typical alternator efficiency of $70 \%$ considerable savings can be achieved.[3] ISG presents better packaging and space utilization and gets rid of belts that are subject to multiple dynamics, lower efficiencies. Fitting an ISG would necessitate multiple modifications to the engine, engine cradle and transmission to accommodate the electric machine in the engine compartment. [2]

\section{INTEGRATED STARTER GENERATOR AS VIABLE SOLUTION}

The ISG fundamentally works as a bi-directional converter for converting mechanical energy to electrical energy and vice versa. [1]An Integrated Starter Generator (ISG) is a component that functions both as starter motor and generator. The ISG can stably satisfy increases in the power demand and it is a key component for realizing additional fuel efficiency improvements owing to its idle stop and go 
function (to reduce fuel consumption when idling) and its potential for regenerative breaking (to recover the vehicle's inertial energy as electric energy when the vehicle decelerates).

In this paper, discussion and study is made to check the feasibility of utilising the existing packaging and to evaluate the benefits of Flywheel Integrated Magneto based Integrated Starter Generator.

\section{A. Scope with ISG}

Owing to the voltage flexibility from $12 \mathrm{~V}$ to 60 volts system, ISG finds its way in the existing IC engines. The following are benefits with ISG

- Starter and Generator in one component

- Ease of cranking less current withdrawn from battery

- Improved current generation over conventional system.

- Minimal changes in the packaging or ease of fitment

- Various option available to meet existing system likewise Flywheel Integrated Magneto based ISG, crankshaft mounted ISG or belt driven ISG.

There are more features for ISG systems which will be explored in subsequent phases of development. These features are auto start stop, regeneration and torque assists. This gives a phase wise path to hybridization of engine applications.

The increase in the number of electric components within the vehicles boosts the market for electrical motors for hybrid and electric vehicles. A Frost \& Sullivan market research finds that the market earned revenues of about 55 million Euros in 2010 , which are expected to reach $\$ 1.6$ billion by the end of 2017 version of this template is V2.[4]

\section{B. Flywheel integrated ISG}

The basic purpose of the ISG model is to provide sufficient starting torque to the system and to rotate the crankshaft to the required speed. At the start, the torque from the ISG is at maximum in order to provide sufficient speed to the crankshaft. As the speed for the crankshaft is increased, the torque of the ISG decreases continuously. The thing which differentiates the ISG from other starters is that the ISG depends on the angular speed. Conventional starters relate to the gearbox through a flywheel because the speed is increased much more than with the ISG starter. [1]

Flywheel magneto generator for a rotary engine that includes a single construction, multi-pole rotor and a three legged Stator, with a magnet provided in the center leg of the Stator and coils provided on the outer legs of the Stator. [7]

\section{CONVENTIONAL STARTING \& CHARGING CIRCUIT}

The conventional system consists of starter motor mounted on engine to crank the engine via rotating the engine through the ring gear. The current is supplied to the starter motor which transfers the torque to engine via ring gear arrangement on flywheel. For one of our applications the measured cranking inrush current was measured to be 706
Amps. This current was needed to produce a torque of $251 \mathrm{Nm}$ for system having starter to current gear ratio of 12.5:1.

$\mathrm{T}=(\mathrm{I} * \mathrm{~V} * 60) /(2 * \mathrm{pi} * \mathrm{RPM})$

$\mathrm{N} 1 / \mathrm{n} 2=\mathrm{t} 2 / \mathrm{t} 1$

Transfer efficiency is considered to $100 \%$ with a system voltage of 12 Volts.

The invention relates to a flywheel magneto generator having a rotor assembly and a Stator assembly. The rotor assembly includes a non-ferromagnetic flywheel and a plurality of magnetic poles that are positioned in spaced relationship around the circumference of the flywheel. The Stator assembly includes a steel core and coils associated with at least the outer legs. The poles and core may be formed of a bonded iron material. The output of the stator is connected to Regulator Rectifier unit. Since the charging current produced by stator is AC in nature and RR unit converts it to DC for charging the battery.

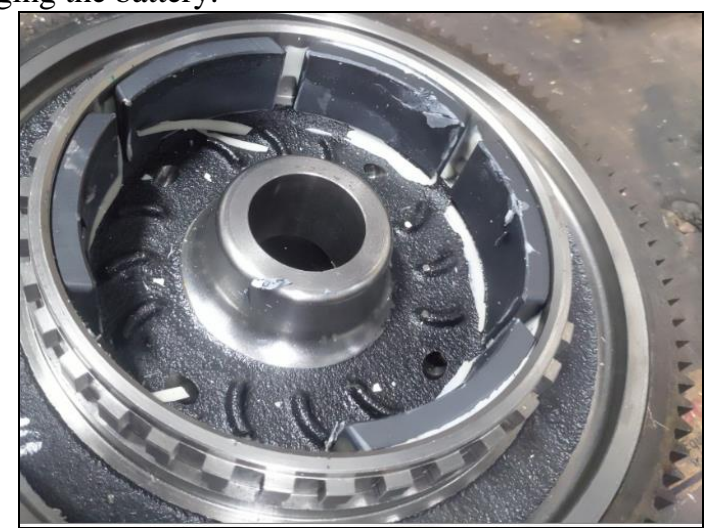

Fig 1 A schematic perspective views of a fly wheel rotor according to the convention;

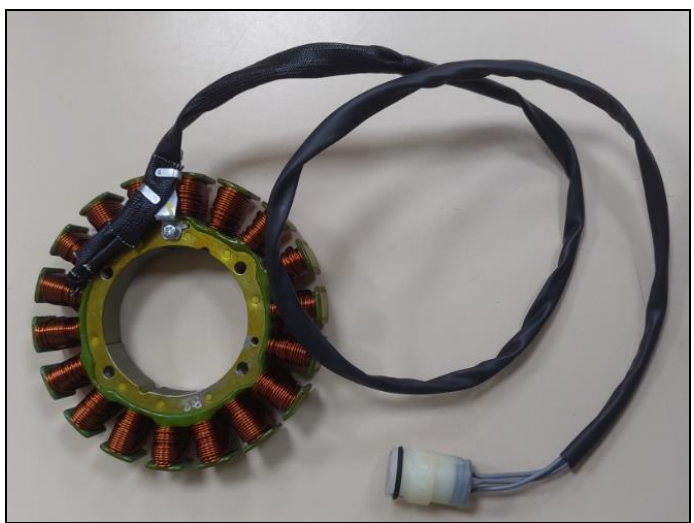

Fig2 A perspective view of a flywheel magneto stator before installed on an engine;

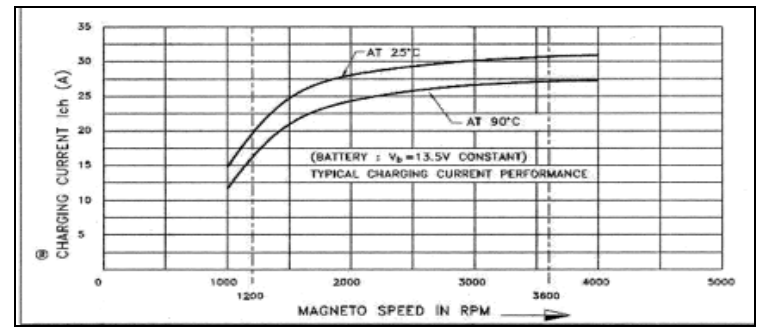

Fig3 A graph showing the output current of a flywheel magneto generator and RR unit for one the single cylinder BS VI three wheeler engine applications. 
For regeneration system the rotor part is generates the rotating magnetic field. Based on this magnetic field the machines are broadly categorized into permanent magnet machine, Induction Machine, Brushless DC and Variable Reluctance Machine (VRM)/ Selective Reluctance Machine (SRM).

In our applications we are using Flywheel Magneto Alternator having a permanent magnet rotor. During engine rotation 12 pole permanent magnets produces a rotating magnetic field around the stator. The 18 pole stator is having varnished copper windings in which current is induced for the charging. These produce 3 -phase alternating current for charging purposes. This charging current is passed through RR unit to get dc output charging current.

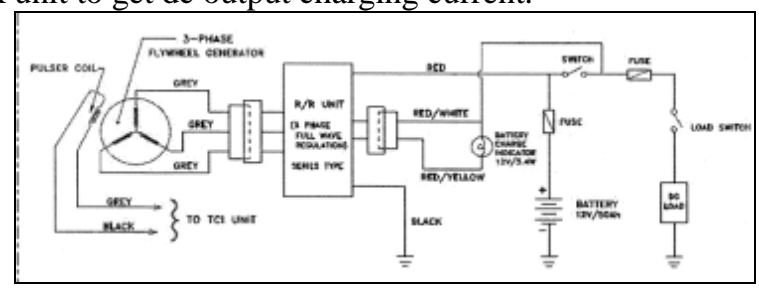

Fig4 A schematic showing convetional charging system

This rotor, stator and RR unit forms the charging circuit and should be designed to meet the electrical energy reqruirements.

\section{A. Alternator Design Improvements}

Migrating towards new generation system the electrical energy requirements is increasing. Also the conventional or the existing system charging system is having efficiency of $50 \%$ to $70 \%$. This gives us potential to improve the charging system. The construction of stator and rotor is similar in our applications. There are number of methods which can be used to improve the alternator efficiency.

- Increasing the number of poles in stator or rotor this will increase the magnetic flux density

- In case the machine is having slots for windings then slot fill techniques are also useful.

- Increase the width of stator core. Using the stainless steel plates in stator core the width can be increased. This will increase the copper wounds thus increasing the alternator efficiency

- A conventional analogue voltage regulator (RR unit) simply increases or decreases the amount of rotor current and provides voltage to an indicator lamp if there is a problem as well as a signal to a microcontroller (MCU). Using the low-cost controller, the alternator regulator can be interfaced to an ECU that manages the charging system to improve operation under a variety of conditions. [8]

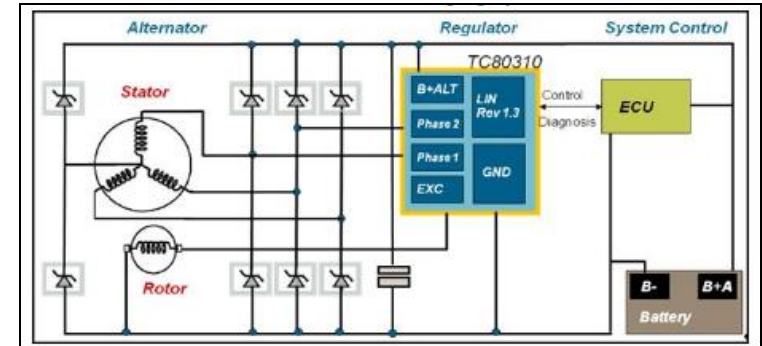

Fig5 the interfaced charging system uses the protocol to communicate control and diagnostic information to the ECU.

In our applications basically improvement in coil windings has been made. This pertains increasing the wounds and decreasing the resistance to get the better efficiency.

\section{ELECTRICAL ENERGY REQUIREMENT}

The electrical loads are broadly categorised into continuous load, prolonged loads (like lamps), intermittent loads and other future requirements. With the above the electrical load requirements is calculated keeping in mind the future requirements also.

Intermittent loads include cranking current which significant current or power for a single crank. With every crank the energy is depleted from the battery. This electrical energy is required to be restored by charging current. The charging current comes from engine which is at the cost of fuel. This is where ISG application pitches in since it has capability to reducing the cranking inrush current, thus improving the electrical energy consumption.

An engine cranking cycle is divided into two parts - at beginning there is large spike of current so as to rotate the engine, this is referred at inrush period. Once it starts rotation there is current required to continue the cranking rpm until it is fired, this is referred as cranking period.

The power required is product of current and voltage for that duration of time.

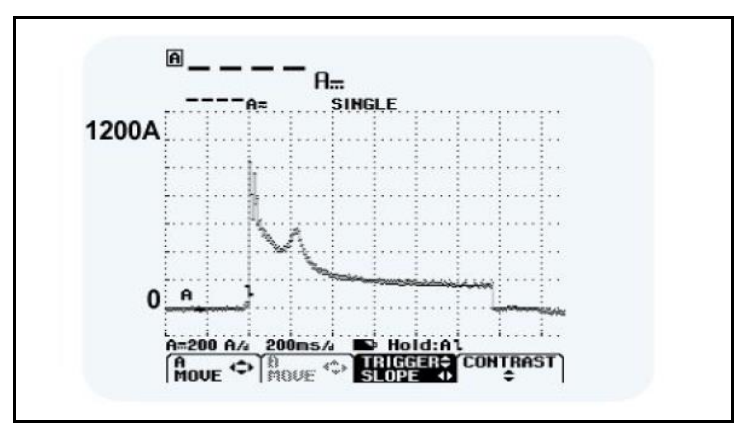

Fig6 Example screen capture from our test equipment showing the inrush spike and then the cranking current versus time [10]

\section{POWER AVAILABLE IN BATTERY}

For most application we are using 12 volts battery with variants of $32 \mathrm{Ah}, 35 \mathrm{Ah}$ and $50 \mathrm{Ah}$. The energy (in $\mathrm{kJ}$ ) available in battery assuming $100 \%$ charges is given by multiplying the amperage with voltage along the time. 
TABLE 1 ENERGY AVAILABLE IN BATTERIES

\begin{tabular}{|c|c|c|c|}
\hline $\begin{array}{c}\text { Battery type } \\
\text { Ah }\end{array}$ & 32 & 35 & 50 \\
\hline & & & \\
\hline $\begin{array}{c}\text { Energy in } \\
\text { Joules }\end{array}$ & 1382400 & 1512000 & 2160000 \\
\hline
\end{tabular}

\section{ISG APPLICATION FOR EXISTING 12V SYSTEM}

For our application an ISG was integrated with Flywheel. Or in other words the FMA assembly was now modified into ISG. It combines the operation of alternator, starter motor and flywheel in a single unit. [9]

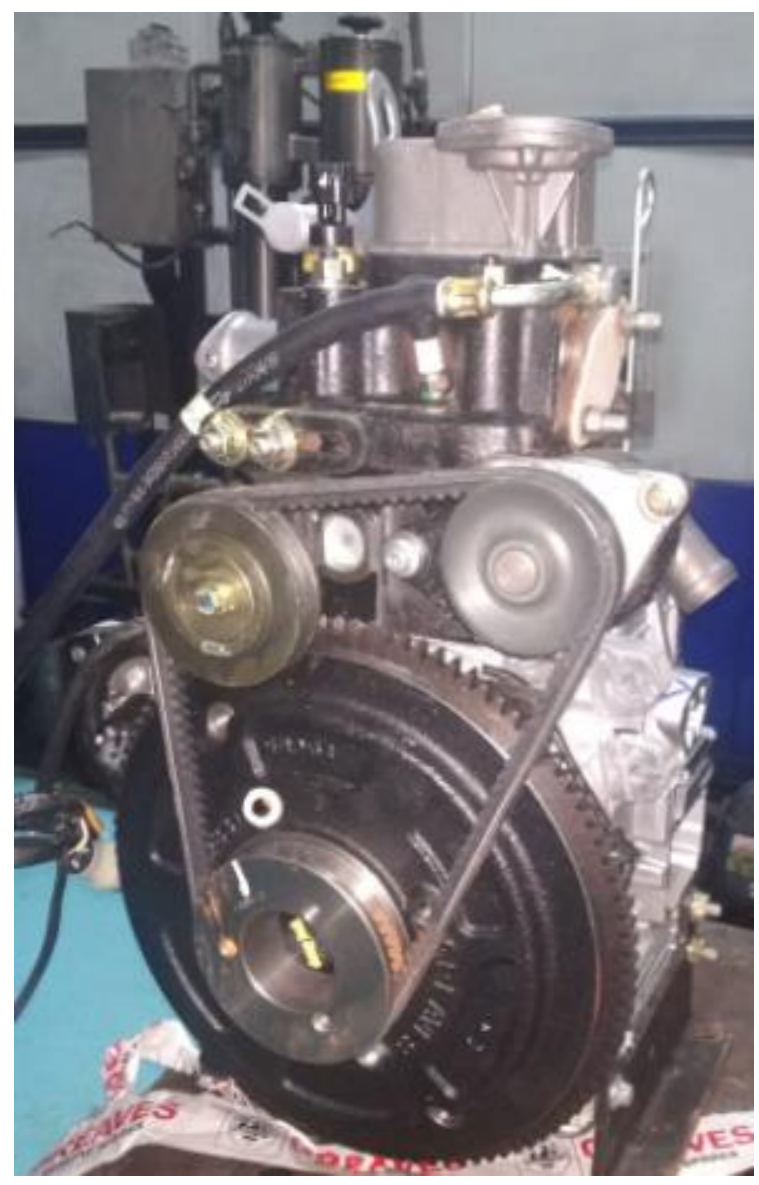

Fig7 Flywheel side view for one the engine applications

ISG in starter mode. The supply is given to the stator and the stator windings create a magnetic field opposite to direction of magnets. This creates the torque and cranking is achieved. Once the cranking is achieved engine can be fired. Once the engine is fired the supply current from stator windings is made zero. And via slip rings or commutators, the charging current is supplied via RR unit to battery.

The above procedure is done using an ISG controller. This controller is used to switch between ISG in starting mode to ISG in generating mode. Also the controller gives the leverage to have features like auto start stop. Depending on the route profile controller can be programmed for regeneration and torque assists functions also.
It results in instant and smooth engine start, improved reliability and also enables idling start feature

\section{TESTING WITH ISG FOR SINGLE CYLINDER APPLICATIONS}

One of our single cylinder engines having FMA was selected for measurement purpose. Initially measurement was done with conventional starting system and then with ISG systems. Results were recorded and analysed for improvements.

Engine cranking was conducted in two conditions that is POT (Part Open Throttle) condition and WOT (Wide Open Throttle) conditions. Recording was made using Picoscope and signals recorded were: -Inrush Current during cranking (Ibatt), Steady Current after inrush (also Ibatt), Cranking Speed ( in rpm),Idle Speed (in rpm)

\section{A. With Conventional starting and charging system.}

In POT conditions

Inrush Current. The peak current is around $706 \mathrm{~A}$ for about $17 \mathrm{~ms}$ with conventional Starter Motor.

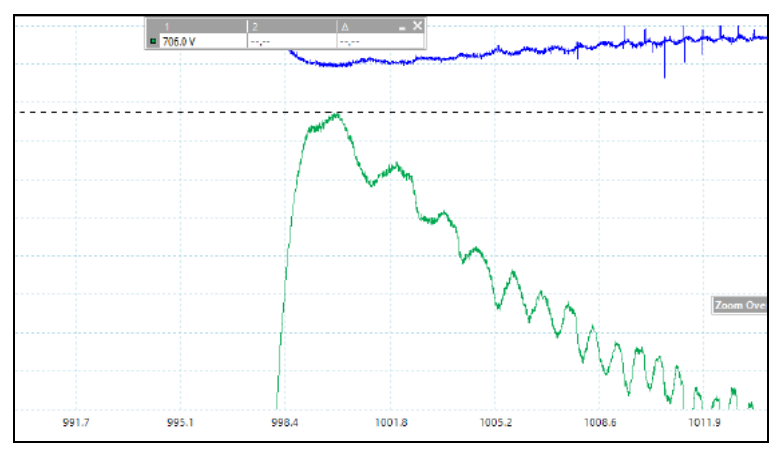

Fig8 Cranking Inrush current with Starter Motor

Cranking steady state Current. The steady current is about $59.5 \mathrm{~A}$ for about 0.35 seconds or $350 \mathrm{~ms}$.

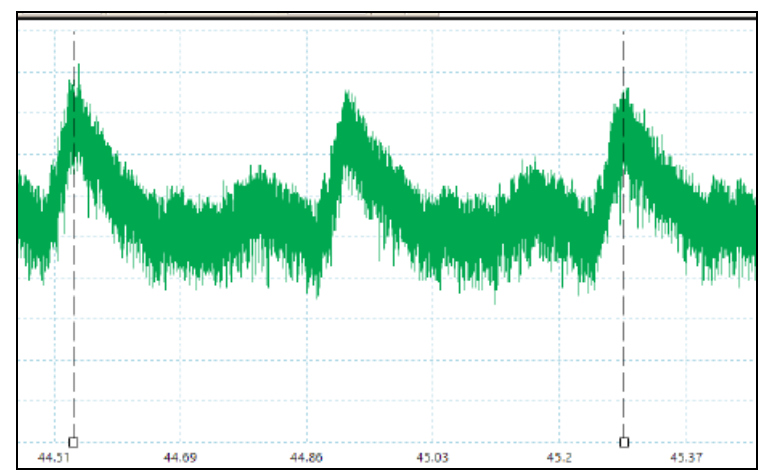

Fig9 Cranking steady current with Starter Motor)

In WOT conditions

Inrush Current. The peak current is around $708 \mathrm{~A}$ for about $358 \mathrm{~ms}$ (or $90 \mathrm{~ms}$ ) with conventional Starter Motor. 


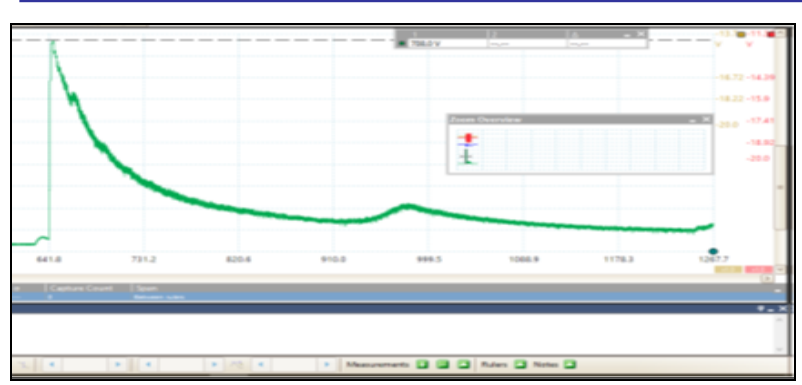

Fig10 Cranking Inrush current with Starter Motor)

Cranking steady state Current. The steady current is about $65 \mathrm{~A}$ for about 230 milliseconds

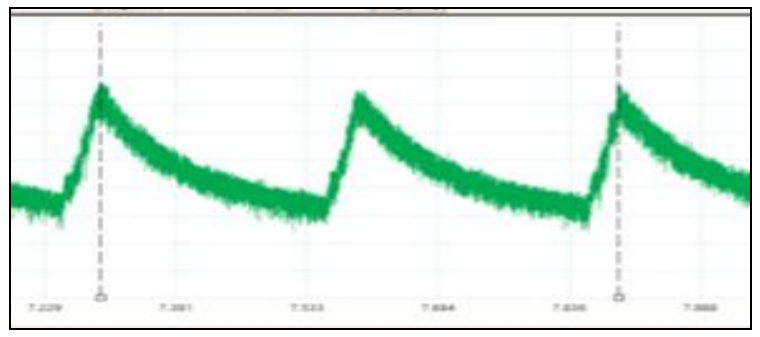

Fig11 Cranking Steady current with Starter Motor

\section{B. With ISG system}

In POT conditions

Inrush current. The peak Current is about 108A for about 20 milliseconds with Flywheel ISG

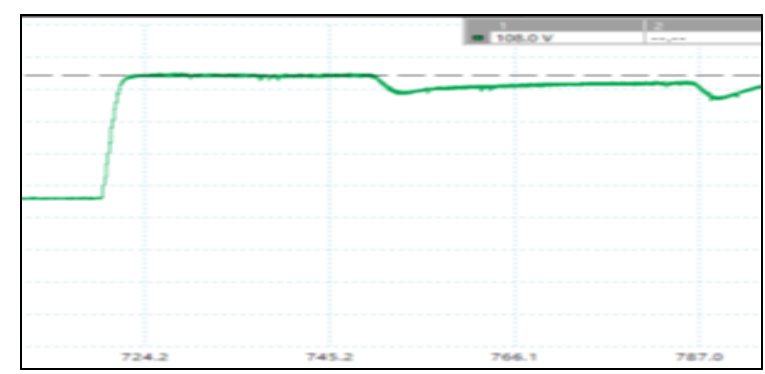

Fig12 Cranking Inrush current with ISG

Cranking steady state Current. The cranking current is $38 \mathrm{~A}$ for about 118.9 milliseconds.

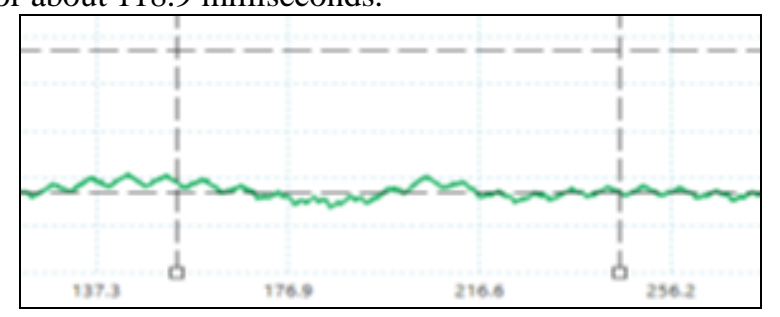

Fig13 Cranking steady current with ISG

In WOT Conditions

Inrush current. The peak Current is about $125 \mathrm{~A}$ for about 50 milliseconds with Flywheel ISG

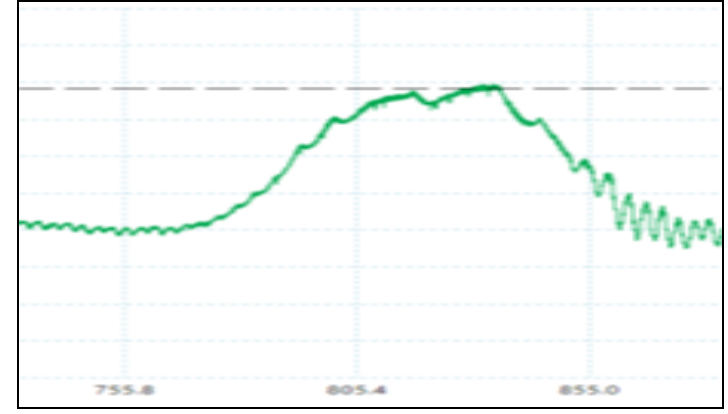

Fig14 Cranking Inrush current with ISG

Cranking steady state Current. The cranking current is $41.2 \mathrm{~A}$ for about 172 milliseconds.

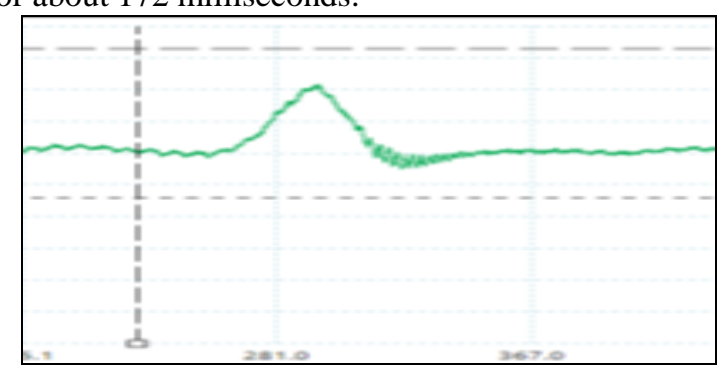

Fig15 Cranking Steady current with ISG

VIII. ENERGY CALCULATIONS

As per data measurements the energy required to crank the engine were calculated. For calculating the energy consumed the area under the current curve method was used. The assumption made was that the battery voltage is 12 Volts. Therefore the power in one crank is product of current voltage and time.

TABLE 2 ENERGY CONSUMPTION COMPARISON WITH ISG AND CONVENTIONAL STARTER

\begin{tabular}{|c|c|c|c|c|c|}
\hline \multicolumn{5}{|c|}{ Assuming a constant supply of 12V } \\
\hline & For Part Open Throttle & & \multicolumn{2}{|c|}{ For Wide Open Throttle } \\
\hline & With & $\begin{array}{c}\text { With Starter } \\
\text { Motor }\end{array}$ & $\begin{array}{c}\text { With } \\
\text { ISG }\end{array}$ & $\begin{array}{c}\text { With Starter } \\
\text { Motor }\end{array}$ \\
\hline $\begin{array}{c}\text { Total Power } \\
\text { (in watts) }\end{array}$ & 1752 & 9186 & & 2004 & 9288 \\
\hline & & & & & \\
\hline $\begin{array}{c}\text { total Energy } \\
\text { (in Joules) }\end{array}$ & 313.008 & 1690.14 & & 161.688 & 946.8 \\
\hline
\end{tabular}

\section{RESULTS}

For single crank the conventional starter uses 1690.14 joules of energy .On the other hand ISG uses only 313.08 joules of energy of single crank.

In terms of wattage ISG utilizes only $2 \mathrm{~kW}$ per crank while conventional takes about $9 \mathrm{~kW}$, which implies that ISG requires 5 times less wattage.

Hence for ISG requires 5 times less energy than conventional starter system. Or per crank we have reduced the electrical energy requirement consumption by cranking the same engine in same time. 
Another dimension to view this number of dead cranks we can get from a fully charged battery. For this let us take $32 \mathrm{Ah}$ battery that is fully charged.

\section{TABLE 3 NUMBER OF CRANKS WITH ISG AND CONVENTIONAL} STARTER SYSTEM

\begin{tabular}{|c|c|c|}
\hline $\begin{array}{c}\text { Energy in fully charged 32Ah } \\
\text { battery (in joules) }\end{array}$ & $\begin{array}{c}\text { Energy Per } \\
\text { Crank with ISG } \\
\text { system (in } \\
\text { joules) }\end{array}$ & $\begin{array}{c}\text { Energy Per Crank } \\
\text { with conventional } \\
\text { system (in joules) }\end{array}$ \\
\hline 1382400 & 320 & 1700 \\
\hline Total number of dead cranks & 4320 & 814 \\
\hline
\end{tabular}

Here also we see that number of dead cranks with ISG has increase by 5 times.

So we see that electrical energy requirement is reduced by using the ISG. This is results in saving the charging current thus saving the fuel costs.

\section{CONCLUSIONS}

With the addition of ISG we saved significant amount of energy required for the electrical energy required for cranking. The energy consumed for one single crank has reduced. The reduced electrical energy consumption is due application ISG. This reduced electrical energy consumption due to improved efficiency during cranking and charging. The electrical energy is provided from the engine or in other words fuel is source for all forms of energy.

Therefore decrease in electrical energy consumption reflects improvement in fuel economy.

\section{ACKNOWLEDGMENT}

My sincere gratitude towards Dr. Ravi Damadoran Chief Technical Officer Research \& Development Greaves Cotton Ltd, Mr Kedar Kanase Senior General Manager, Advance Engineering Research \& Development, Greaves Cotton Ltd and $M r$. Phaneesh K Associate General Manager, Advance Engineering Research \& Development, Greaves Cotton Ltd.

I am thankful the our team members Mr. Prathamesh Kudalkar Assistant Manager Advance Engineering, Greaves Cotton Ltd, Mr. Ashwin G Assistant Manager Advance Engineering, Greaves Cotton Ltd, and Mr. Parashram Patil GET Advance Engineering, Greaves Cotton Ltd. I would like to thank the Team members for making significant contribution in testing and development throughout the project.

\section{REFERENCES}

[1] Peachy Essay. "A simulation of an engine start- stops system with an integrated starter generation by decreasing dampening effects and developing control technique."

[2] Dennis Sabina Kibalama, Graduate Program in Electrical and Computer Science, The Ohio State University, Design and Implementation of a Belted Alternator Starter System for the OSU EcoCAR 3 Vehicle.

[3] Markus Örn, Master thesis at Scania, Linköping, Sweden. "Towards better alternator efficiency," June2014.

[4] The Frost \& Sullivan, Strategic Analysis of Electric Motor Technologies for Electric and Hybrid Vehicles in Europe. http://www.automotive.frost.com [Accessed: 6-January 2017].

[5] Moo-Yeon Lee, Dong Hyun Lim and Sung Chul Kim 3Article"Evaluation of the Effect of Operating Parameters on Thermal Performance of an Integrated Starter Generator in Hybrid Electric Vehicles". Energies March 2015.

[6] Jingbo Liu, M.S.E.E, The Ohio State University, Dissertation "MODELING, ANALYSIS AND DESIGN OF INTEGRATED STARTER GENERATOR SYSTEM BASED ON FIELD ORIENTED CONTROLLED INDUCTION MACHINES.” 2005.

[7] Peter Campbell, Raleigh, NC (US); David Johnston Miller, Apex NC (US). "FLYWHEEL MAGNETO GENERATOR." United States Patent Application Publication Pub. No.: US 2003/0127922 A1Pub. Date: Jul. 10, 2003

[8] Jean-Philippe Meunier and David Lopez, Freescale Semiconductor, "to reduce vehicle power consumption and increase efficiency, start at the charging system", 28th Oct 2018.

[9] Arthi, Priyadharshini, Radhika, Sarah Silvia Pinky, "Electronic Controller for generating mode of Integrated Starter-Generator -Two Wheeler Application.” Vol. 7, Issue 3, March 2018

[10] Blue Sea System- Blue Sea Systems Engine Starting Standards; "https://www.bluesea.com/resources/114." 